\title{
Optimizing iron delivery in the management of anemia: patient considerations and the role of ferric carboxymaltose
}

This article was published in the following Dove Press journal:

Drug Design, Development and Therapy

II December 2014

Number of times this article has been viewed

\section{Jorge Eduardo Toblli \\ Margarita Angerosa}

Nephrology Section, Department of Internal Medicine, Hospital Alemán, School of Medicine, University

of Buenos Aires, Argentina
Correspondence: Jorge Eduardo Toblli Laboratory of experimental Medicine, Hospital Alemán, School of Medicine, University of Buenos Aires, Av Pueyrredon, 1640, III8 Buenos Aires, Argentina

Tel +54 || 48277000 ext 2785

Fax +54 II 48056087

Email jorgetoblli@fibertel.com.ar
Abstract: With the challenge of optimizing iron delivery, new intravenous (iv) iron-carbohydrate complexes have been developed in the last few years. A good example of these new compounds is ferric carboxymaltose (FCM), which has recently been approved by the US Food and Drug Administration for the treatment of iron deficiency anemia in adult patients who are intolerant to oral iron or present an unsatisfactory response to oral iron, and in adult patients with non-dialysisdependent chronic kidney disease (NDD-CKD). FCM is a robust and stable complex similar to ferritin, which minimizes the release of labile iron during administration, allowing higher doses to be administered in a single application and with a favorable cost-effective rate. Cumulative information from randomized, controlled, multicenter trials on a diverse range of indications, including patients with chronic heart failure, postpartum anemia/abnormal uterine bleeding, inflammatory bowel disease, NDD-CKD, and those undergoing hemodialysis, supports the efficacy of FCM for iron replacement in patients with iron deficiency and iron-deficiency anemia. Furthermore, as FCM is a dextran-free iron-carbohydrate complex (which has a very low risk for hypersensitivity reactions) with a small proportion of the reported adverse effects in a large number of subjects who received FCM, it may be considered a safe drug. Therefore, FCM appears as an interesting option to apply high doses of iron as a single infusion in a few minutes in order to obtain the quick replacement of iron stores. The present review on FCM summarizes diverse aspects such as pharmacology characteristics and analyzes trials on the efficacy/safety of FCM versus oral iron and different iv iron compounds in multiple clinical scenarios. Additionally, the information on cost effectiveness and data on change in quality of life are also discussed.

Keywords: intravenous iron, iron deficiency, anemia, ferric carboxymaltose

\section{Importance of treating anemia and understanding iron metabolism}

Based on the World Health Organization reports, anemia is one of the most frequent and widespread disorders in the world, affecting $>1.6$ billion people, which results in an estimated global prevalence of almost $25 \% .^{1}$ Anemia impacts upon more than half the preschool children and pregnant women in developing countries and at least $30 \%-40 \%$ in developed countries. Additionally, a high prevalence of anemia is associated with the elderly ${ }^{2}$ and with acute as well as chronic conditions. ${ }^{3}$

Although several factors such as vitamin deficiencies (A, B12, folic acid), infectious diseases (parasites), chronic inflammation, and genetic disorders may cause anemia, iron deficiency is undoubtedly the most common cause of anemia worldwide. ${ }^{4}$ Notably, iron deficiency affects not only red blood cell production but also cellular functions related to muscle metabolism, mitochondrial function, neurotransmitters, DNA synthesis, and the immune system. ${ }^{5}$ Iron deficiency syndromes include "absolute 
iron deficiency" (absence of storage iron), "functional iron deficiency" (insufficient iron incorporation into erythroid precursors with adequate body iron stores), and "iron sequestration" (stored iron not able to be used); the coexistence of these conditions in some patients often complicates their diagnosis and management. ${ }^{6}$

\section{Brief concepts on iron metabolism}

The total body iron amount $(\sim 3-4 \mathrm{~g})$ is regulated by a subtle balance between body requirements, iron supply (absorption of dietary), and blood losses. ${ }^{7}$ The absorption of dietary iron is a dynamic process that varies somewhat according to the body's need for iron. Moreover, environmental and genetic factors may also elicit diverse influences in this process. The amount of iron absorbed is usually low, but may fluctuate from $10 \%$ to $35 \%$ depending on a variety of situations and the class of iron (Figure 1). ${ }^{8}$ The efficiency with which iron is absorbed varies depending on the source. The best absorbed form of iron is heme iron, which comes from animal products and some plant products (absorption from 15\% to $35 \%$ of the intake). The duodenal epithelial cell is probably the main place where the iron is absorbed, although every part of the small intestine is involved in this process. Notably, a powerful stimulus for iron absorption is hypoxia. This triggers a sensible pathway in which the hypoxia inducible factor $2 \alpha$ has a capital role. ${ }^{9}$

Dietary $\mathrm{Fe}^{3+}$ is first reduced to $\mathrm{Fe}^{2+}$ by duodenal cytochrome $b$, the enzyme present in the apical brush border of the enterocyte with ferric reductase activity. Then, it is transported to the enterocytes' cytoplasm via the divalent metal transporter 1 (DMT1) (Figure 2). ${ }^{10}$

Concerning heme iron, there is some evidence supporting that the heme is taken up by receptor-mediated endocytosis by heme carrier protein $1 .{ }^{11-13}$

Internalized heme is metabolized by heme oxygenase 2 inside the vesicles generating biliverdin and carbon monoxide and releasing non-heme iron. Then, the iron is transferred to the cytoplasm via DMT1 (Figure 2). Once Fe ${ }^{2+}$ enters the cell,

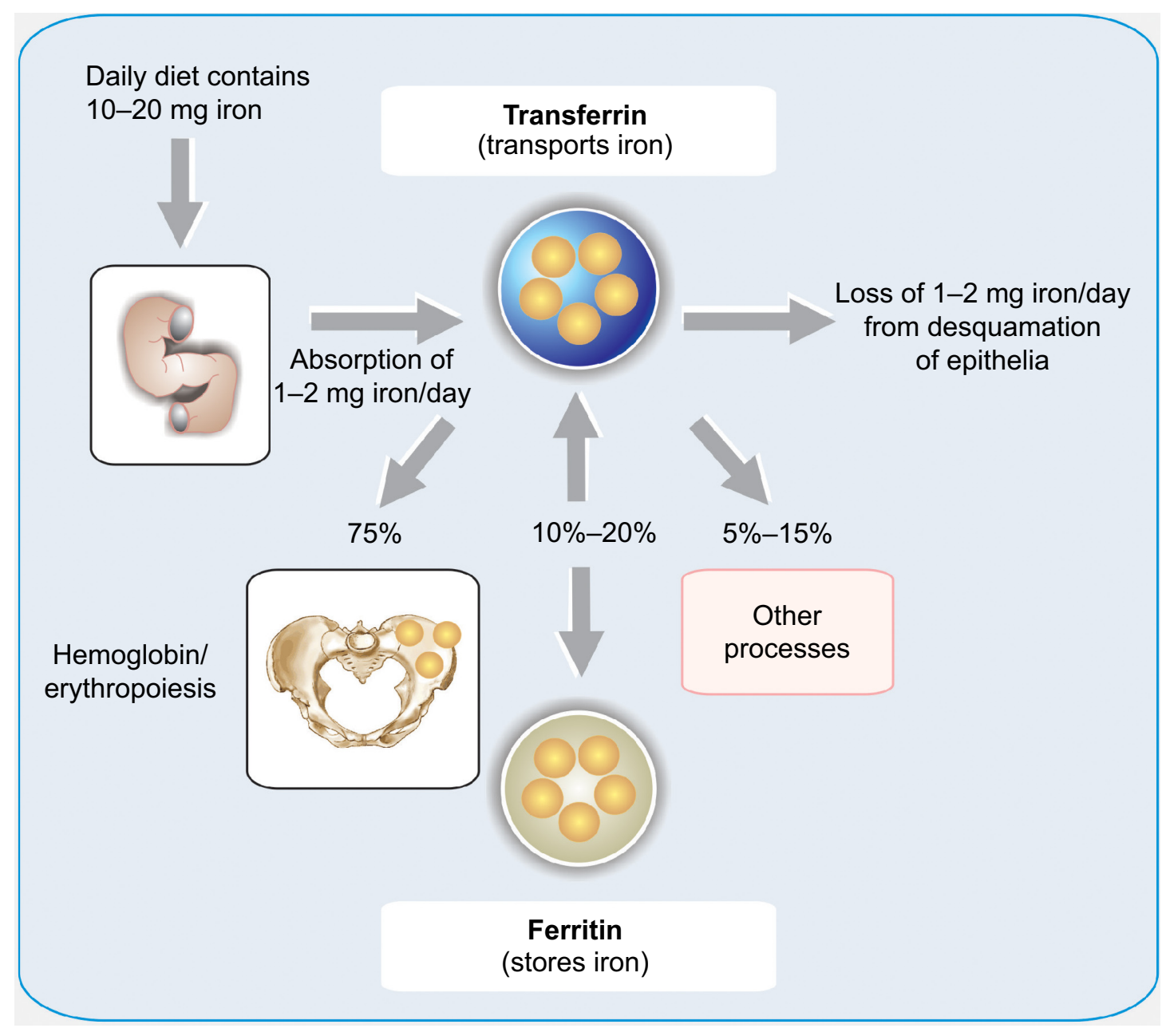

Figure I Diagram of iron input, output, and distribution in the body. 
it can be utilized for cellular processes, stored in ferritin, or leave the cell via ferroportin (FPN). ${ }^{14}$ The FPN-mediated outflow of $\mathrm{Fe}^{2+}$ from intestinal cells and also macrophages into the plasma is essential for iron homeostasis. Hepcidin, a peptide hormone synthesized by liver cells, negatively regulates this process. Hence, hepcidin binds to FPN and increases its phosphorylation, internalization, and lysosomal digestion (Figures 2 and 3). ${ }^{15}$ Hepcidin transcription is inhibited during anemia throughout a pathway that requires erythropoietic activity. ${ }^{16}$
On the other hand, interleukin 6 (IL6) promotes hepcidin transcription by signal transducer and activator of transcription 3 phosphorylation and translocation to the nucleus for binding to a proximal promoter element with the support of an active BMP/HJV/SMAD pathway. ${ }^{17}$ Extracellular iron is bound with high affinity by transferrin (TF) (Figure 2). Since there is no active iron excretion process in the body, iron homeostasis is regulated by intestinal iron absorption and by macrophage iron recycling. The most important mechanism of cellular

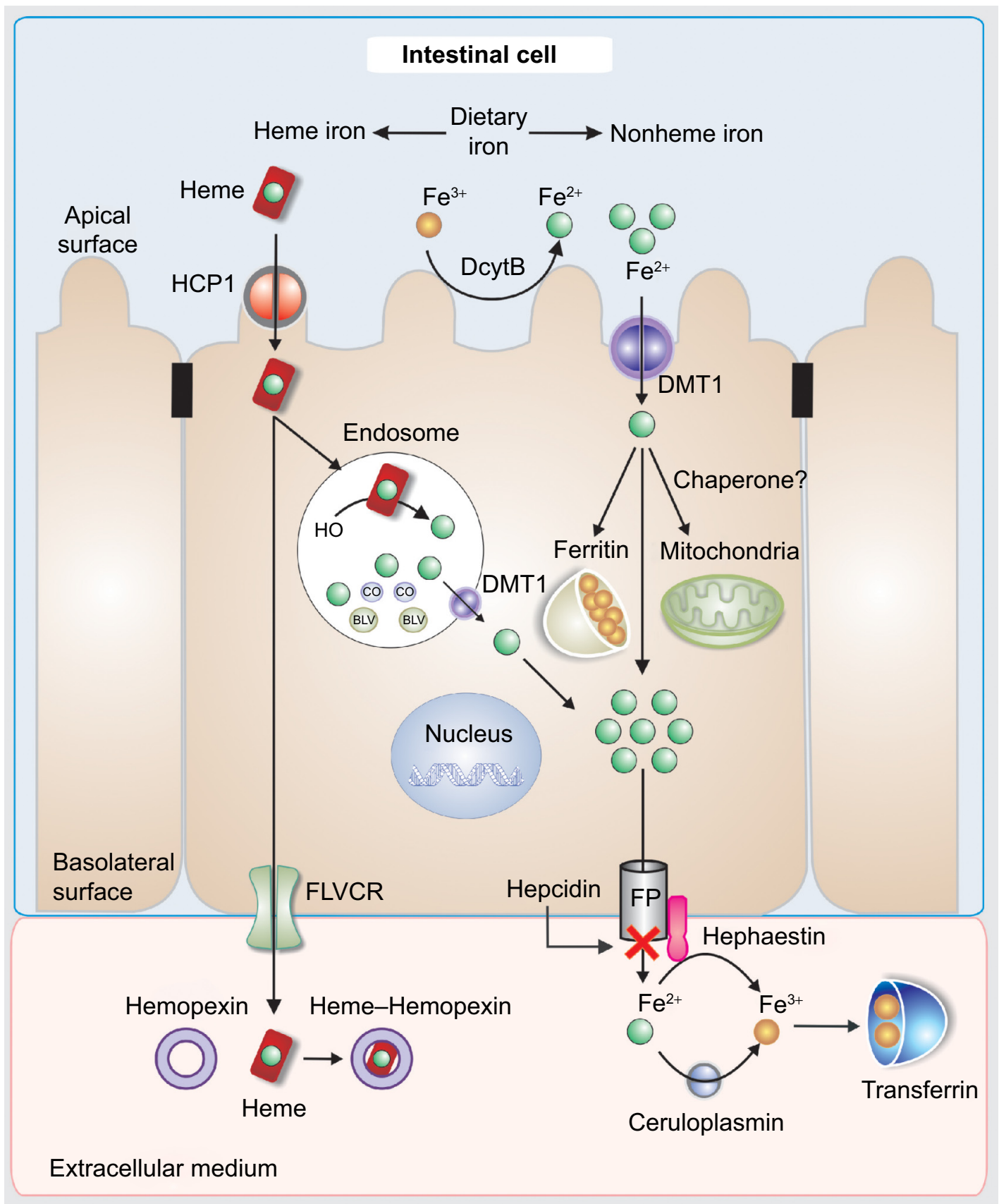

Figure 2 Scheme of iron transport in the enterocyte. Absorption, intracellular distribution, and exit to the extracellular medium.

Abbreviations: BLV, biliverdin; CO, carbon monoxide; DcytB, duodenal cytochrome B; DMTI, divalent metal transporter I; FP, ferroportin; FLVCR, feline leukemia virus subgroup $\mathrm{C}$ receptor; $\mathrm{HCPI}$, heme carrier protein I. 


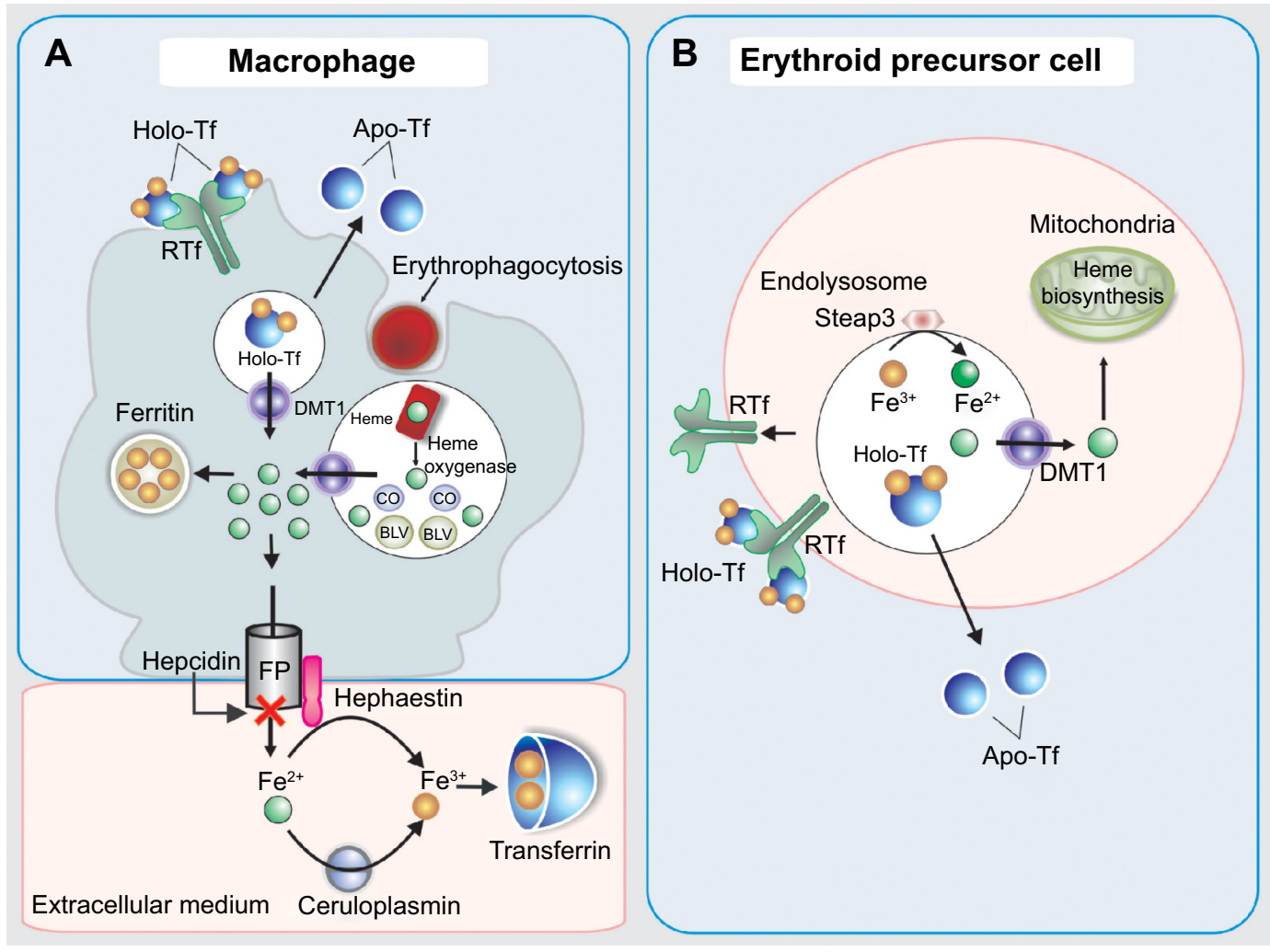

Figure 3 Scheme of iron transport and metabolism in the macrophage (A) and in erythroid precursor cell (B).

Abbreviations: BLV, biliverdin; CO, carbon monoxide; DMTI, divalent metal transporter I; FP, ferroportin; HCPI, heme carrier protein I.

iron outflow is iron recycling from senescent red blood cells by macrophages (Figure 3A). These cells process the heme iron, which is returned to the circulation for reutilization by erythroid precursor cell during red blood cell production. Such mechanism supplies more than $90 \%$ of all the iron required in physiological processes and erythropoiesis. ${ }^{18,19}$ Notably, during ID, the amount of iron released is greater than that delivered for storage as ferritin. It is accepted that the iron release from macrophages is due to the free diffusion of intracellular labile iron $\left(\mathrm{Fe}^{2+}\right)$ throughout the plasma membrane via FPN. ${ }^{20}$ Outside the cell, ceruloplasmin induces the transformation from $\mathrm{Fe}^{2+}$ to $\mathrm{Fe}^{3+}$ (Figure 3A). Apo-TF binds $\mathrm{Fe}^{3+}$ to form mono- $\mathrm{Fe}^{3+}$ and di-Fe ${ }^{3+} \mathrm{TF}$ (Figure $3 \mathrm{~A}$ ).

According to the passive-gradient model, the removal of $\mathrm{Fe}^{2+}$ from the site of release sustains the gradient that maintains the iron release. Therefore, the macrophages elicit a central role in the iron handling, not only from an endogenous source, like dietary iron via enterocyte and iron recycling from senescent erythrocytes, but also in the case of intravenous (iv) iron administration.

The erythroid precursors obtain iron through TF receptormediated endocytosis of holo-TF. Then, the iron is transferred to the cytoplasm via DMT1 and later to the mitochondria for its use in heme biosynthesis (Figure 3B). The importance of TF in mammalian iron metabolism is firmly established. In this sense, studies in hypotransferrinemic mice, a model of inherited TF deficiency, have demonstrated the paramount role of TF in the iron delivery for erythropoiesis and in the regulation of hepcidin expression. ${ }^{21}$ Therefore, the lack of TF-mediated iron delivery to the erythron is associated with the occurrence of anemia.

\section{Pharmacology overview of iv iron compounds}

To restore the body iron levels in clinical practice, several iv iron formulations are currently available. The main properties and pharmacology characteristics of each iv iron compound are compared in Table 1.

The iv iron preparations are made of iron-carbohydrate complexes (ICCs), which are composed of a polynuclear iron(III)-oxyhydroxide/oxide core surrounded by a carbohydrate ligand, which stabilizes the complex and preserves it against further polynuclearization. ${ }^{23}$ The ICCs could be considered as prodrugs, since the iron has to be released from the polynuclear core to become available at its site of action. At present, the metabolism of ICCs inside macrophages and 


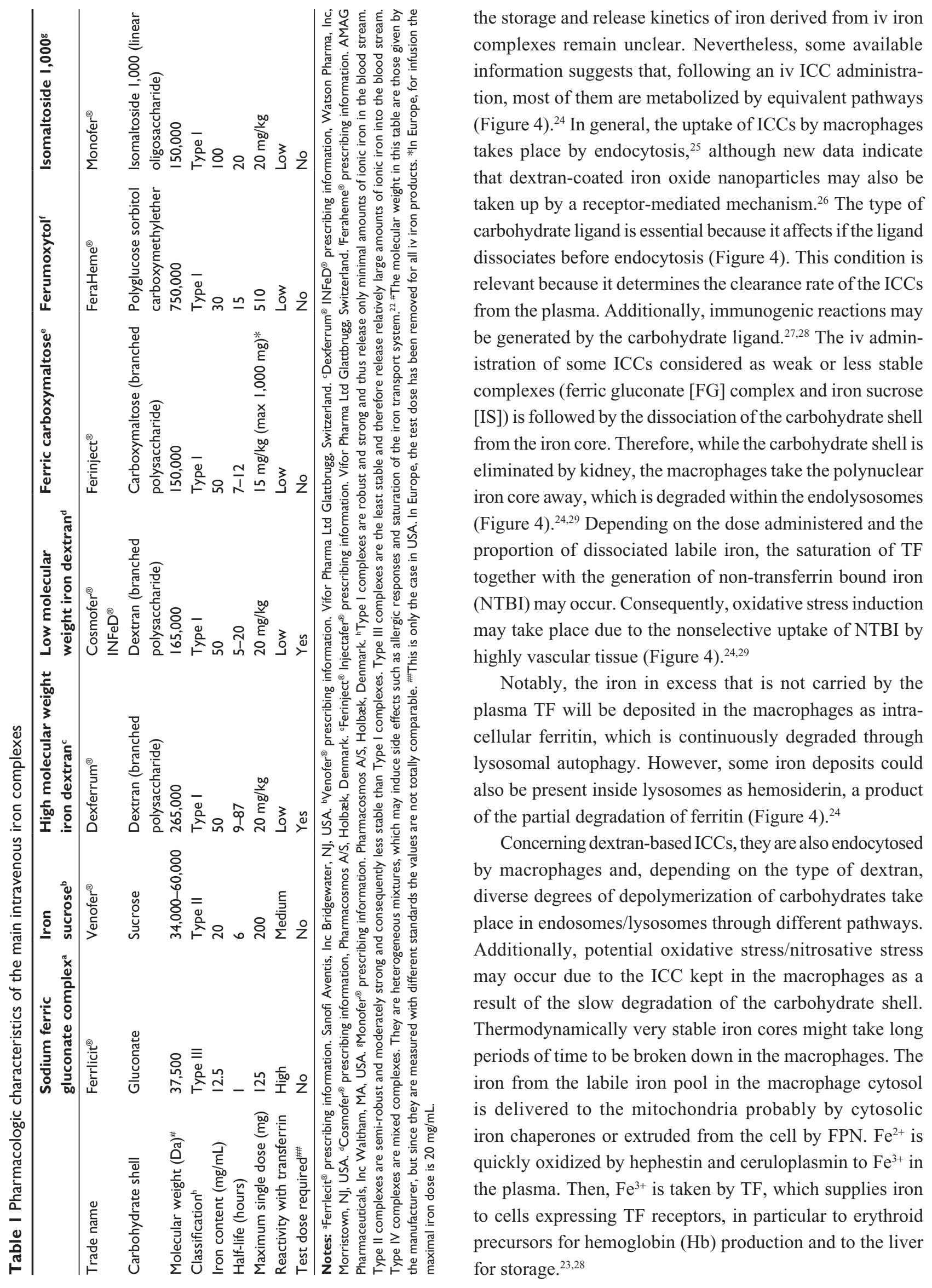

Drug Design, Development and Therapy 20।4:8

submit your manuscript | www.dovepress.com 


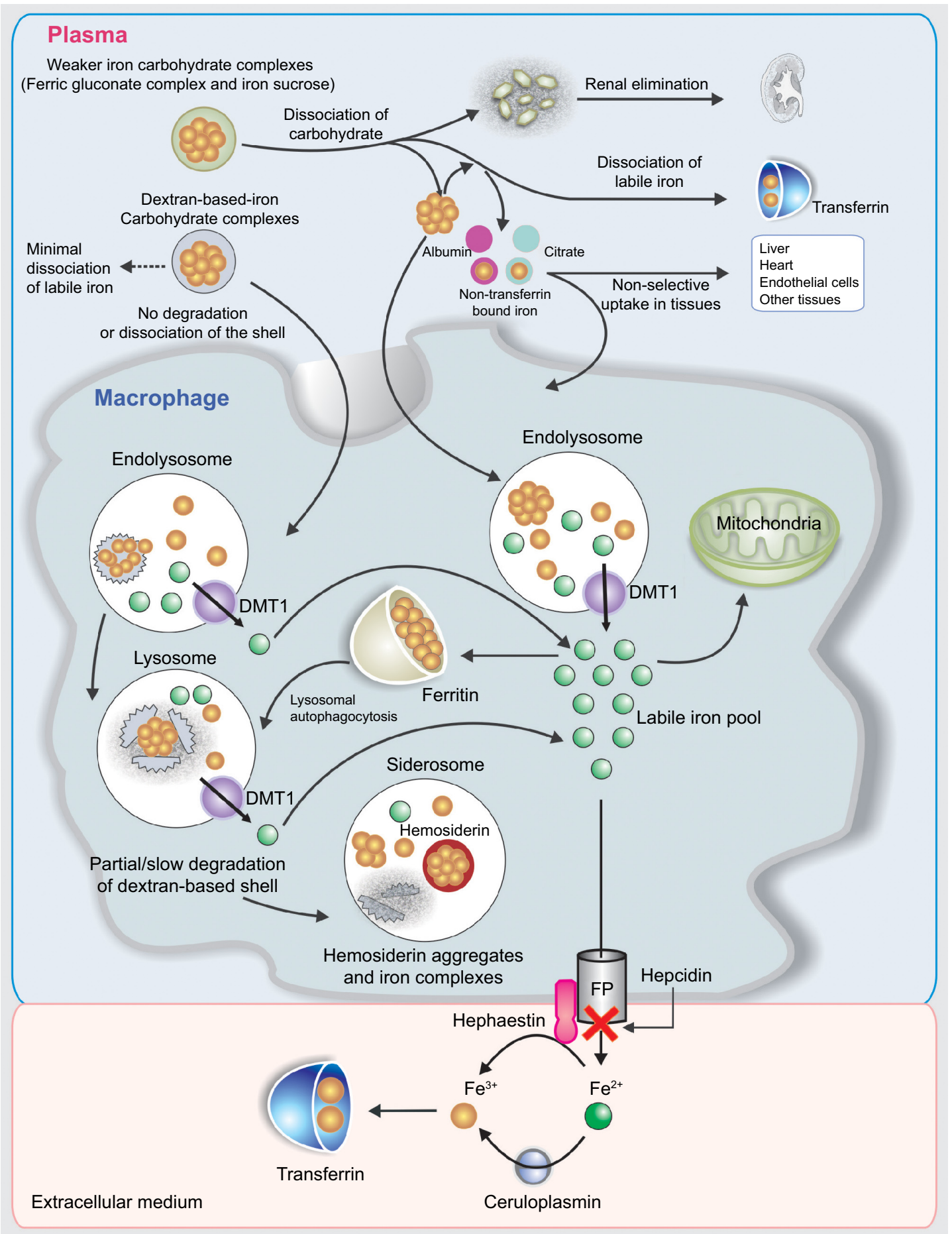

Figure 4 Schematic sequence illustrating the metabolism of iron-carbohydrate complexes.

Note: Data from Koskenkorva-Frank et al. ${ }^{24}$

Abbreviations: DMTI, divalent metal transporter I; FP, ferroportin.

\section{Ferric carboxymaltose}

Ferric carboxymaltose (FCM) is a new iv iron formulation. It is a polynuclear iron(III)-hydroxide carbohydrate complex designed to mimic physiologic ferritin. FCM is a water-soluble, brown, amorphous powder with a relative molecular weight of $150,000 \mathrm{Da}$, containing approximately 1,000 iron atoms, which corresponds to an iron content of $24 \%-32 \%$, together with $25 \%-50 \%$ dextrin, $\leq 10 \%$ water, and $<6 \% \mathrm{NaCl}$. It is $\mathrm{pH}$ neutral (5-7) and has physiologic osmolarity. FCM does not contain dextran or modified dextran and does not react with dextran antibodies. ${ }^{30}$ 
After iv FCM administration, the carbohydrate shell is incompletely broken down in the blood by $\alpha$-amylase, as illustrated in Figure 5.

Then, macrophages take the FCM by an endocytic mechanism by which the carbohydrate shell and the polynuclear iron core may be completely broken down in the endolysosomes to release $\mathrm{Fe}^{3+}$. Then, six-transmembrane epithelial antigen of the prostate 3 (Steap3) is likely to reduce the released $\mathrm{Fe}^{3+}$ into $\mathrm{Fe}^{2+}$ (Figure 5). ${ }^{31}$

$\mathrm{Fe}^{2+}$ is extruded from the endolysosomes to the cytosolic labile iron pool by the activity of DMT1 and from the cytosol to the plasma by FPN. Finally, it is transported by TF (Figure 5 ) to the liver, bone marrow, and other tissues.

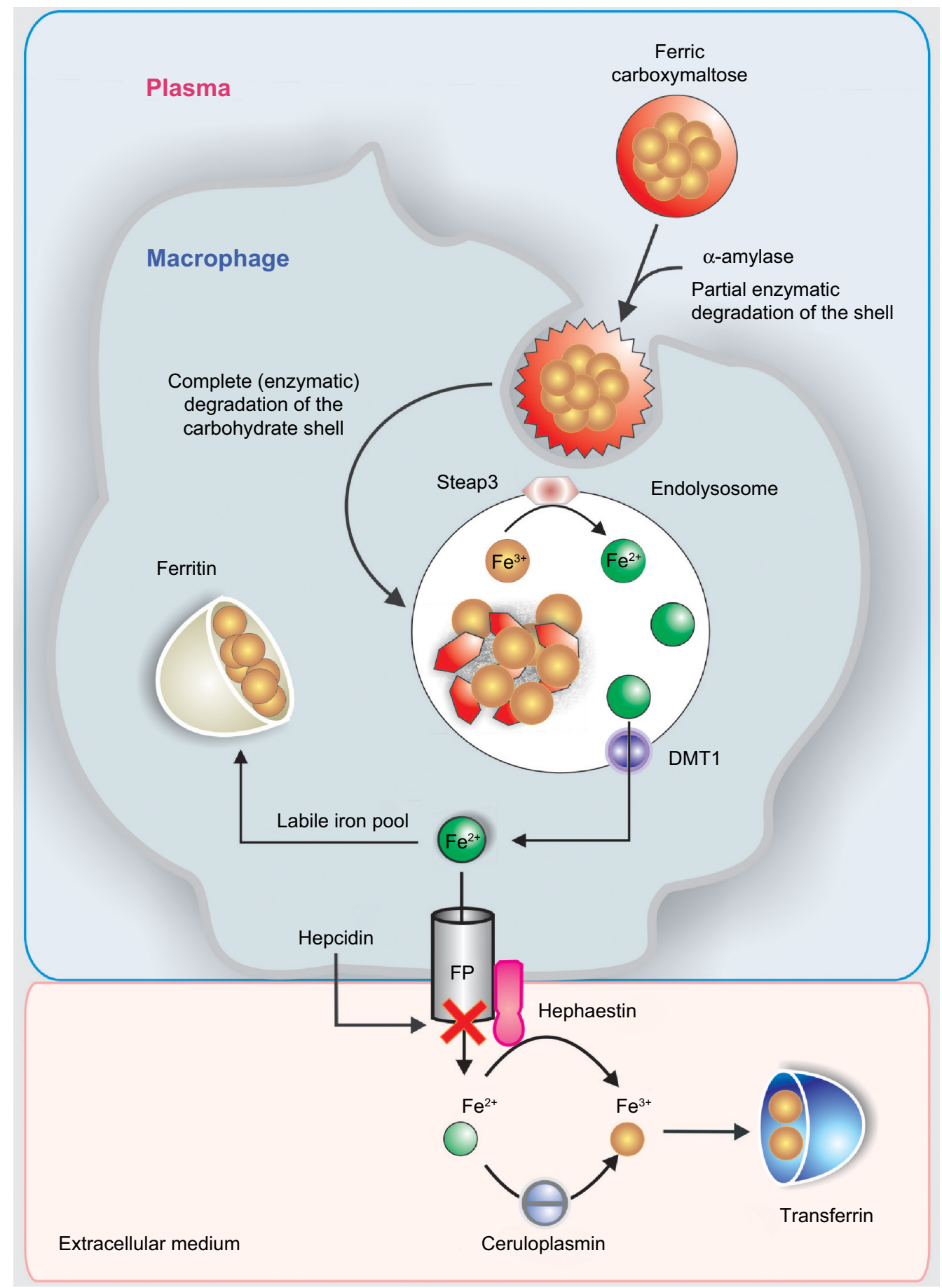

Figure 5 Schematic sequence illustrating the metabolic pathway of ferric carboxymaltose in the macrophage. Abbreviations: DMTI, divalent metal transporter I; FP, ferroportin. 
Four ascending doses were investigated in a total of 24 patients with mild IDA: $100 \mathrm{mg}$ iron as FCM given as an iv bolus injection, and $500 \mathrm{mg}, 800 \mathrm{mg}$, and 1,000 $\mathrm{mg}$ iron as FCM given as an iv infusion over 15 minutes. ${ }^{32}$ Assessments were made of pharmacokinetic iron status parameters up to 168 hours post dose. In comparison with placebo, a rapid, dose-dependent rise in total serum iron was observed across all dose groups. Peak serum iron levels occurred within 0.3-1.2 hours. Mean maximum total serum iron levels were $36.9 \mu \mathrm{g} / \mathrm{mL}$ following a $100-\mathrm{mg}$ iv dose, $154.1 \mu \mathrm{g} / \mathrm{mL}$ following a 500-mg iv dose, and 306.4-317.9 $\mu \mathrm{g} / \mathrm{mL}$ following a 1,000-mg iv dose. ${ }^{32}$

Iron supplied as FCM is quickly provided to different tissues, mainly to the bone marrow, liver, and spleen, the volume of distribution being approximately 3 L. Following the administration of an i.v. dose of FCM, the level of total serum iron presents a reduction between 24 hours and 72 hours. After 60-96 hours post FCM infusion, most patients show total serum iron levels under the limit of quantification. Concerning serum ferritin, a dose-dependent, but not doselinear, increase maybe observed within 48-120 hours post FCM dose, with maximum levels of a 23-210-fold increase above baseline level. ${ }^{32}$

In an uncontrolled multidose study in patients with moderate IDA secondary to gastrointestinal disorders, ${ }^{33}$ a 15-min infusion of either FCM (500 mg iron) weekly for up to 4 weeks or FCM (1,000 mg iron) weekly for up to 2 weeks resulted in maximum serum iron levels of $154 \mu \mathrm{g} / \mathrm{mL}$ and $306 \mu \mathrm{g} / \mathrm{mL}$ at 1 hour post dose, respectively, and returned to baseline values at 4-7 days. Before the following dose, serum iron levels stayed within the normal level, and no change was observed with repeated infusions. ${ }^{33}$ Following a single infusion of FCM $100 \mathrm{mg}$ labeled with ${ }^{52} \mathrm{Fe} /{ }^{59} \mathrm{Fe}$ as a tracer in patients with IDA or anemia related to chronic kidney disease (CKD), a rapid increase of radiolabeled iron incorporation from FCM into red blood cells was observed by the first 6-9 days. ${ }^{34}$ Additionally, after 24 days, iron incorporation was greater (91\%-99\%) in IDA patients than in those with renal anemia $(61 \%-84 \%)$. iron was quickly removed from plasma and mostly delivered to the liver, spleen, and bone marrow, but bone marrow showed a much higher iron uptake.

Most iron administered as FCM is utilized or eliminated within 24 hours (100-mg dose) or 72 hours (500-1,000-mg dose). The clearance for FCM appears to be essentially monoexponential, suggesting that iron as FCM is not deposited in a body store from where it could diffuse back to the serum. FCM has a terminal elimination half-life of 7.4-12.1 hours.
Less than $0.01 \%$ of the administered dose is excreted in urine. Concerning breastfed infants, there were no adverse effects reported..$^{35}$

\section{Clinical studies evaluating the efficacy of FCM Studies with FCM in anemic patients with CKD}

It is recognized that iron deficiency is the most relevant reason for the hyporesponsiveness of erythropoietin stimulating agents (ESAs) in CKD. ${ }^{36}$ The administration of ESAs considerably raises the costs of CKD management. Therefore, high relevance must be given to enhancing responsiveness to ESAs in order to ensure the maximum benefit for patients. Several studies with FCM in patients with IDA and CKD have been performed in order to evaluate its efficacy and safety. ${ }^{37-42}$ In a multicenter, open-label study, Covic and Mircescu ${ }^{37}$ investigated the efficacy of FCM given as a bolus push injection into the hemodialysis (HD) venous line (2-3 times/week for $\leq 6$ weeks) in HD-CKD patients. The treatment was well tolerated, and $61.7 \%$ of the patients were treatment responders with a total cumulative dose of iron as FCM of 2,133.3 $\pm 57.7 \mathrm{mg}$. The mean $\mathrm{Hb}$ levels increased from $9.1 \pm 1.30 \mathrm{~g} / \mathrm{dL}$ at baseline to $10.3 \pm 1.63 \mathrm{~g} / \mathrm{dL}$ at follow-up.

More recently, in a cohort of HD and NDD-CKD adult patients, Charytan et $\mathrm{al}^{38}$ evaluated the safety and efficacy of FCM versus the standard medical care (oral iron, IS, or FG). The HD-CKD patients received single doses of $200 \mathrm{mg}$ FCM, while NDD-CKD patients received up to $1,000 \mathrm{mg}$. The FCM in a dose of $200 \mathrm{mg}$ for HD-CKD patients and up to $1,000 \mathrm{mg}$ in NDD-CKD patients was well tolerated and showed similar efficacy to other iv iron compounds. The incidences of serious adverse events (AEs) were higher in patients receiving standard medical care with IS or FG.

The first and largest comparison study of two iv iron therapies for the treatment of IDA in patients with NDDCKD was the REPAIR-IDA. ${ }^{39}$ It was a randomized, activecontrolled, multicenter, noninferiority, open-label trial with a total of 2,584 participants, which assessed the efficacy and cardiovascular safety of two 750-mg infusions of FCM versus 200-mg IS given in up to five infusions in 14 days in patients with IDA and NDD-CKD. The mean change to highest $\mathrm{Hb}$ from baseline to day 56 and primary composite safety endpoint, which included all-cause mortality and other $\mathrm{CV}$ morbidities, were evaluated. The mean $\mathrm{Hb}$ increase was $1.13 \mathrm{~g} / \mathrm{dL}$ in the FCM group versus $0.92 \mathrm{~g} / \mathrm{dL}$ in the IS group. More patients in the FCM group obtained an $\mathrm{Hb}$ increase of $\geq 1.0 \mathrm{~g} / \mathrm{dL}$ from baseline to day 56 (48.6\% versus $41.0 \%$ ). 
There was no significant difference between FCM and IS concerning the primary composite safety endpoint. However, transient hypertensive episodes were recorded in the FCM group. Two 750-mg infusions of FCM demonstrated to be a safe and effective alternative to multiple, lower dose IS infusions in NDD-CKD patients with IDA. Additionally, the study showed that two single-dose infusions of FCM may potentially provide more effective iron administration, reduce healthcare costs, and increase patient compliance compared with multiple-dose IS in NDD-CKD patients with IDA.

Some studies have compared FCM versus oral iron in NDD-CKD patients. The efficacy and safety of high doses of FCM, given iv over 15 minutes, versus oral ferrous sulfate (FS) in NDD-CKD patients was evaluated in a Phase III, open-label, randomized, controlled, multicenter trial. ${ }^{40}$ The percentage of subjects obtaining an $\mathrm{Hb}$ increase $\geq 1 \mathrm{~g} / \mathrm{dL}$ at any time was $60.4 \%$ with FCM and $34.7 \%$ with oral iron $(P<0.001)$. At day 42 , the mean rise in $\mathrm{Hb}$ was $0.95 \pm 1.12 \mathrm{~g} / \mathrm{dL}$ versus $0.50 \pm 1.23 \mathrm{~g} / \mathrm{dL}(P<0.01)$; the mean increase in ferritin was $432 \pm 189 \mathrm{ng} / \mathrm{mL}$ versus $18 \pm 45 \mathrm{ng} / \mathrm{mL}(P<0.01$; and the mean rise in transferrin saturation (TSAT) was $13.6 \% \pm 11.9 \%$ versus $6.1 \% \pm 8.1 \%(P<0.01)$. AEs were significantly fewer with FCM versus oral iron $(2.7 \%$ and $26.2 \%$, respectively, $P<0.01)$.

Undoubtedly, the longest randomized trial of iv iron therapy to date is the FIND-CKD study. It is a 56-week, open-label, multicenter, prospective and randomized study of 626 patients with NDD-CKD, IDA not receiving ESAs. ${ }^{41}$ The increase in $\mathrm{Hb}$ was greater with high-ferritin FCM versus oral iron $(P<0.02)$ and more patients obtained an $\mathrm{Hb}$ increase of $\geq 1 \mathrm{~g} / \mathrm{dL}$ with high-ferritin FCM versus oral iron (HR: 2.04; 95\% CI: 1.52-2.72; $P<0.001$ ). Rates of AEs were similar in all groups. Compared with oral iron, FCM targeting a ferritin level of $400-600 \mu \mathrm{g} / \mathrm{L}$ quickly reached and maintained the $\mathrm{Hb}$ level and delayed and/or reduced the need for other anemia management including ESAs.

\section{Studies with FCM in patients with chronic heart failure (CHF)}

Anker et $\mathrm{al}^{43}$ led a randomized controlled trial of 459 patients with CHF of the New York Heart Association (NYHA) functional class II or III, a left ventricular ejection fraction (LVEF) of $45 \%$ or less, iron deficiency (ferritin level $<100 \mu \mathrm{g} / \mathrm{L}$ or $100-299 \mu \mathrm{g} / \mathrm{L}$, whether TSAT was $<20 \%$ ), and an $\mathrm{Hb}$ level of 9.5-13.5 g/dL. The patients received $200 \mathrm{mg}$ of FCM or saline. The self-reported Patient Global Assessment (PGA) and NYHA functional class at week 24 were the primary endpoints, and the distance walked in
6 minutes (6MWT) and the health-related quality of life (QoL) were included as secondary end points. At week 24, the ferritin, TSAT, and $\mathrm{Hb}$ values were significantly different between the two study groups $(P<0.001$ for all comparisons). However, the mean difference in the $\mathrm{Hb}$ level was only significant among patients who had anemia at baseline $(0.91 \pm 0.22 \mathrm{~g} / \mathrm{dL}, P<0.001)$. Twice the number of patients with FCM reported being much better or moderately improved, versus those receiving placebo, according to the PGA (OR for improvement: 2.51; CI: 1.75-3.61). Forty-seven percent of those patients with FCM presented an NYHA functional class I or II at week 24 versus $30 \%$ of the patients in the placebo group (OR for improvement by one class: 2.40; CI: 1.55-3.71). Interestingly, the outcomes were not different in patients with and without anemia. Substantial positive changes were found after iv FCM in the QoL assessments and also in the 6MWT distance. The AEs were similar in both groups. The treatment with iv FCM in patients with $\mathrm{CHF}$ and iron deficiency, with or without anemia, improved the symptoms, functional capacity, and QoL.

Following the FAIR-HF study, ${ }^{43}$ several subanalyses have emerged with positive results in favor of the FCM treatment. ${ }^{44-47}$ In one of them, the relationship between red cell distribution width (RDW), a new prognostic marker in patient with CHF, and 6MWT distance was assessed. ${ }^{44}$ Data from 415 patients on RDW values and 6MWT distance at baseline and at least one follow-up visit (after 4 weeks, 12 weeks, and 24 weeks) were analyzed. The main finding was that iron deficiency in CHF was associated with high RDW, and that the treatment with FCM in these patients decreased RDW. Additionally, the 6MWT distance and RDW were inversely related at baseline $(r=-0.30, P<0.01)$. The improvement in 6MWT distance at 24 weeks was significantly correlated with a reduction in RDW ( $r=-0.25$, $P<0.01)$ in patients with FCM.

A recent new study, the CONFIRM-HF ${ }^{48}$ was designed in order to test the benefits and safety of long-term iv therapy with FCM in patients with iron deficiency with CHF. It was a multicenter, double-blind, placebo-controlled trial that enrolled 304 ambulatory symptomatic CHF patients with $\mathrm{LVEF} \leq 45 \%$, elevated natriuretic peptides, and iron deficiency (ferritin $<100 \mathrm{ng} / \mathrm{mL}$ or $100-300 \mathrm{ng} / \mathrm{mL}$ if TSAT $<20 \%$ ). Patients were treated with FCM or placebo saline for 52 weeks. The primary endpoint was the change in 6MWT distance from baseline to week 24. Secondary endpoints included changes in NYHA class, PGA, 6MWT distance, health-related QoL, fatigue score at weeks 6, 12, 24,36 , and 52, as well as the effect of FCM on the rate of 
hospitalization for worsening CHF. The treatment with FCM significantly prolonged 6MWT distance at week 24 (difference FCM vs placebo: $33 \pm 11 \mathrm{~m}, P=0.002)$. The treatment effect of FCM was consistent in all subgroups and was sustained for up to week 52 (difference FCM vs placebo: $36 \pm 11 \mathrm{~m}, P<0.01)$. Throughout the study, an improvement in NYHA class, PGA, QoL, and the fatigue scores in patients treated with FCM was detected with statistical significance observed from week 24 onward. Therapy with FCM was related to a marked reduction in the risk of hospitalizations for worsening CHF (OR: 0.39 [CI: 0.19-0.82], $P=0.009$ ). The number of deaths was FCM: 12 and placebo: 14 deaths, and the incidence of AEs was similar in both groups. The treatment of symptomatic ID CHF patients with FCM over a 1-year period was related to a sustainable improvement in the functional capacity, symptoms, and QoL and may be associated with the reduction of risk of hospitalization for worsening $\mathrm{CHF}$.

\section{Studies with FCM in patients with gastrointestinal disorders}

A multicenter, open label, randomized, controlled Phase III study was globally performed in 36 sites in eight countries in order to evaluate the noninferiority and safety of FCM in comparison with oral FS in diminishing IDA in inflammatory bowel disease (IBD). ${ }^{49}$ Two hundred patients were randomized for receiving FCM (maximum 1,000 mg iron/ infusion) at 1-week intervals until the patients' calculated total ID was achieved or FS (100 mg bid) for 12 weeks. The aim of the study was to monitor the change in $\mathrm{Hb}$ from baseline to week 12 . The delta median $\mathrm{Hb}$ improvement in the FCM group was $3.6 \mathrm{~g} / \mathrm{dL}$ and $3.0 \mathrm{~g} / \mathrm{dL}$ in the oral group, this showing no inferiority $(P=0.69)$. Response was higher for FCM at week $2(P<0.01)$ and week $4(P=0.034)$. While median ferritin increased from $5.0 \mu \mathrm{g} / \mathrm{L}$ to $323.5 \mu \mathrm{g} / \mathrm{L}$ at week 2 , in the FCM group a mild increase from $6.5 \mu \mathrm{g} / \mathrm{L}$ to $28.5 \mu \mathrm{g} / \mathrm{L}$ at week 12 was found in the FS group. Although a similar proportion of AEs occurred in both groups (FCM: $28.5 \%$ and FS: $22.2 \%$ ), the discontinuation of the study medication due to AEs was five times higher in FS. The main conclusions of this study were that FCM was efficient and safe in IBD-associated anemia, and it was not inferior to FS with respect to $\mathrm{Hb}$ change after 12 weeks, leading to a quick $\mathrm{Hb}$ elevation and an adequate refill of iron deposits.

In an observational study (range: 12-29 months), Befrits et $\mathrm{al}^{50}$ assessed how gastroenterologists follow the guidelines in IBD patients treated with FCM, as well as the result of this therapy in Sweden. A total of 14 centers included 394 IBD patients (Crohn's disease 60\%, ulcerative colitis 40\%). Median values for $\mathrm{Hb}$, ferritin, and TSAT at baseline were $11.1 \mathrm{~g} / \mathrm{L}, 10 \mathrm{mmol} / \mathrm{L}$, and $10 \%$, respectively, and $13.4 \mathrm{~g} / \mathrm{L}$, $121 \mathrm{mmol} / \mathrm{L}$, and 20\% after FCM $(P<0.001$ for all three parameters). Approximately three-quarters of all the patients had only one iron infusion during the study period, and the median time for reinfusion was $6(1-25)$ months. The effect on iron parameters of FCM was significant and resulted in a ferritin level that indicated an effect on the iron stores. The effect was mostly sustained for a year because only one-quarter of the patients were given repeated iron infusions. No unforeseen safety concerns emerged during the observation period.

Kulnigg-Dabsch et $\mathrm{al}^{51}$ explored the effect of FCM on platelet count and activity in IBD-associated thrombocytosis, which is considered a marker of the active disease and may contribute to the increased thromboembolic risk in such patients. The study was a randomized, single-blinded, placebocontrolled trial testing the effect of FCM in patients with IBD with secondary thrombocytosis (platelets $>450,000 / \mu \mathrm{L}$ ). Changes in platelet counts, $\mathrm{Hb}$, iron parameters, disease activity, megakaryopoietic growth factors, erythropoietin, and platelet activity were assessed. Patients received placebo or up to $1,500 \mathrm{mg}$ iron as FCM, and the endpoints were evaluated at week 6 . A total of 26 patients were enrolled in this study, and 15 patients were available for the per protocol analysis. A drop in platelets $>25 \%$ (primary endpoint) was observed in four out of eight patients ( $50 \%$, iron group) and one out of seven patients ( $14 \%$, placebo group, $P=0.143$ ). Mean platelet counts dropped on FCM but not on placebo $(536,000-411,000 / \mu \mathrm{L}$ versus 580,000-559,000/ $\mu \mathrm{L} ; P<0.01)$. Disease activity and megakaryopoietic growth factors stayed stable, and $\mathrm{Hb}$ and iron parameters rose on FCM. The improvement of platelet counts was associated with a reduction in platelet aggregation and p-selectin expression.

With the purpose of evaluating the effectiveness and safety of a novel fixed-dose FCM therapeutic schedule versus IS in patients with IBD and IDA, Evstatiev et al ${ }^{52}$ conducted a randomized, controlled, open-label, multicenter study. More than 400 patients with IDA (ferritin $<100 \mu \mathrm{g} / \mathrm{L}$, $\mathrm{Hb} 7-12 \mathrm{~g} / \mathrm{dL}$ for females or $7-13 \mathrm{~g} / \mathrm{dL}$ for males) and mild-to-moderate or quiescent IBD were enrolled in 14 countries. Patients received either FCM in a maximum of three infusions of 1,000 mg or $500 \mathrm{mg}$ iron, or Ganzonicalculated IS dosages in up to eleven infusions of $200 \mathrm{mg}$ iron. The change in $\mathrm{Hb}$ (increase $\geq 2 \mathrm{~g} / \mathrm{dL}$ ) was the primary endpoint, whereas the normalization of both $\mathrm{Hb}$ and iron status by week 12 were secondary endpoints. Most patients 
in the FCM group (65.8\%) achieved the primary endpoint versus those in the IS group $(53.6 \%) P<0.01$, or Hb normalization $(72.8 \%$ ) versus $(61.8 \%) P<0.02$, respectively. Both therapeutic schedules enhanced the QoL scores by week 12 . More deviations from the scheduled total iron dosages were observed In the IS group. the researchers concluded that a therapeutic scheme based on FCM was more efficient with better patient compliance together with a satisfactory safety profile in comparison with the Ganzoni-calculated IS dose regimen. More recently, the same research group performed another controlled study to determine whether administration of FCM may prevent anemia in patients with IBD and low levels of serum ferritin. ${ }^{53}$ The main conclusions of this trial were that FCM prevents the recurrence of anemia in patients with IBD, compared with placebo.

FAIRY (NCT01725789) will be a randomized, controlled, patient-blind, Phase III study to evaluate the effectiveness and safety of FCM versus placebo in patients with acute isovolemic anemia after gastrectomy. ${ }^{54}$ The primary endpoint will be an increase in $\mathrm{Hb}$ level by $2 \mathrm{~g} / \mathrm{dL}$ at 12 weeks after randomization. A total of 450 patients ( 225 per group) will be subjected to the administration of either FCM (treatment group) or normal saline (placebo group). Patients will be blinded to the intervention, and a hematology and QoL assessment will be performed at 3 weeks and 12 weeks after randomization. The expectation of this study is to address whether the administration of FCM is superior to placebo for anemia correction without the possible risks of red blood cell transfusion. Furthermore, improved QoL for patients with quick recovery of $\mathrm{Hb}$ levels is expected.

\section{Studies with FCM in patients with anemia related to gynecological and obstetrics disorders}

Van Wyck et $\mathrm{al}^{55}$ conducted a randomized, controlled trial to assess the efficacy of iv FCM versus oral FS in the management of anemia in more than 400 women with anemia, ID, and heavy uterine bleeding (HUB). The patients received either iv FCM $(\leq 1,000 \mathrm{mg}$ over 15 minutes, repeated weekly to obtain a full calculated supplement dose) or $325 \mathrm{mg}$ of FS (65 mg elemental iron) orally thrice daily for 6 weeks. Compared to those assigned to FS, more patients in the FCM group presented an increase in $\mathrm{Hb}$ of $2.0 \mathrm{~g} / \mathrm{dL}$ or more $(82 \%$ vs $62 \%, P<0.001$ ), obtained an increase in $\mathrm{Hb}$ of $3.0 \mathrm{~g} / \mathrm{dL}$ or more $(53 \%$ vs $36 \%, P<0.001)$, and achieved anemia correction $(73 \%$ vs $50 \%, P<0.001)$. More vitality and less fatigue $(P<0.05)$ were reported by patients treated with FCM in comparison with those receiving FS. No severe AEs were reported, and it was concluded that FCM was more effective than FS in resolving anemia, refilled iron deposits, and enhancing QoL in patients with IDA due to HUB.

Recently, Herfs et $\mathrm{a}^{56}$ performed a multicenter, prospective, noninterventional study on the efficacy and tolerance of FCM use in ordinary gynecological practice. The data from $\sim 300$ patients with iron deficiency or IDA were evaluated.

The etiologies of iron deficiency/IDA were hypermenorrhea, postpartum condition, or other causes. FCM was most frequently (92\%) administered by infusion (average 21 minutes), and in $7 \%$ of the patients by bolus injections.

The average total iron dosage was $788.7 \mathrm{mg}$ (range: 50-3,000 mg)/patient and the median individual dosage was $500 \mathrm{mg}$ (range: $50-1,000 \mathrm{mg}$ )/patient. In most cases, the total dosage was given as single application. The increase in $\mathrm{Hb}$ value was $2.5 \mathrm{~g} / \mathrm{dL}$ in the whole group. However, in the IDA group, the value increase was $3.4 \mathrm{~g} / \mathrm{dL}$, with $80 \%$ of women reaching normal $\mathrm{Hb}$ values. TSAT values and serum ferritin were also increased $(16.3 \%-22.8 \%$ and $17.2-88.8 \mu \mathrm{g} / \mathrm{L}$, respectively). No severe AEs were reported.

The role of FCM in pregnancy has been evaluated in some studies. There is general consensus in considering IS as a safe ICC to be used in the treatment of pregnant women with IDA. However, since the total iron dose usually requires numerous applications, the $\mathrm{Hb}$ target for an individual patient is not always achieved. Hence, in a retrospective analysis of 206 pregnant women who received either FCM or IS for IDA due to intolerance to oral iron substitution or insufficient $\mathrm{Hb}$ increase after oral iron treatment, Christoph et al $^{57}$ evaluated comparatively the side effects and tolerance of these two ICCs. Mild AEs were reported in 7.8\% for FCM and 10.7\% for IS. The mean rise of $\mathrm{Hb}$ value was $1.5 \mathrm{~g} / \mathrm{dL}$ for FCM and $1.1 \mathrm{~g} / \mathrm{dL}$ for IS. FCM had a similar safety profile to IS, with the advantage of a higher iron dosage at a time, this diminishing the requirement of multiple administrations.

On this background, a recent prospective observational study was performed to test the safety and effectiveness of FCM in treating pregnant women with mild, moderate, and severe IDA in the second and third trimester. ${ }^{58} \mathrm{~A}$ total of 65 anemic pregnant women were treated with FCM between 24 weeks and 40 weeks of pregnancy. The FCM efficacy was tested by changes in $\mathrm{Hb}$ and by a report of the patients' well-being in the postpartum period. The fetal heart rate and occurrence of AEs were recorded during the infusion as a safety evaluation. A significant $(P<0.01)$ rise in $\mathrm{Hb}$ was observed after FCM administration in all women. This positive $\mathrm{Hb}$ change was found at 3 weeks and 6 weeks post 
FCM application and in some cases up to 8 weeks. Moreover, serum ferritin also increased after FCM administration. No negative impact of the drug on the fetus was observed. Two-thirds of the interviewed women reported an improvement in their well-being, and one-third did not perceive any substantial modifications following FCM application. The rate of mild AEs was $20 \%$.

There are some studies with FCM in postpartum anemia. In three of them, FCM was compared to oral iron ${ }^{59-61}$ and in one versus IS. ${ }^{62}$ In a randomized, open label, controlled trial, Van Wyck et al ${ }^{59}$ estimated the efficacy of FCM $(\leq 1,000 \mathrm{mg}$ over 15 minutes, repeated weekly to achieve a total calculated replacement dose) compared with oral iron therapy (FS, $325 \mathrm{mg}$ orally tid for 6 weeks) in anemic women ( $\mathrm{Hb} \leq 10.0 \mathrm{~g} / \mathrm{dL})$ within 10 days postpartum. One-hundred and seventy-four patients received 350 iv doses of FCM (mean total dose $1,403.1 \mathrm{mg}$ ) in three, two, or one injection $(10.9 \%, 79.3 \%$, or $9.8 \%$ of patients, respectively); 178 received FS. Although an equivalent proportion of patients in both groups obtained an increase in $\mathrm{Hb} \geq 2.0 \mathrm{~g} / \mathrm{dL}$, the therapeutic response was earlier with FCM (7.0 days vs 14.0 days, $P<0.001)$. Additionally, the FCM group was more likely to normalize $\mathrm{Hb}(90.5 \%$ vs $68.6 \%, P<0.001)$. There were no serious AEs. In conclusion, FCM was an effective therapy for postpartum anemia. Moreover, in comparison with FS, FCM showed a quicker response and was better tolerated.

Another study was a multicenter, randomized, controlled one, including 291 women with $<10$ days after delivery with $\mathrm{Hb} \leq 10 \mathrm{~g} / \mathrm{dL}$. The patients received FCM $(\mathrm{n}=143) \leq 1,000 \mathrm{mg}$ over 15 minutes or less, repeated weekly to a calculated replacement dose (maximum 2,500 $\mathrm{mg}$ ) or FS $(\mathrm{n}=148)$ $325 \mathrm{mg}$ orally tid for 6 weeks. ${ }^{58}$ FCM-treated subjects were significantly more likely to achieve an $\mathrm{Hb}>12 \mathrm{~g} / \mathrm{dL}$ in a shorter time period with a sustained $\mathrm{Hb}>12 \mathrm{~g} / \mathrm{dL}$ at day 42 . Additionally, these patients achieved an $\mathrm{Hb}$ rise of $3 \mathrm{~g} / \mathrm{dL}$ faster than those with FS, together with higher TSAT and ferritin levels. Drug-related AEs occurred less frequently with FCM.

Breymann et $\mathrm{al}^{35}$ conducted a multicenter $(20$ centers in three countries), open-label, randomized, and controlled Phase III study in women with postpartum IDA $(\mathrm{Hb} \leq 10.5 \mathrm{~g} / \mathrm{dL})$. The patients were randomized to receive FCM (up to three weekly doses of 1,000 mg maximum, applied in 15 minutes; $\mathrm{n}=227$ ) or FS (100 mg bid, 12 weeks; $\mathrm{n}=117$ ). Both therapeutic regimens were equally effective in changing the $\mathrm{Hb}$ value. However, in the case of FCM, there was a shorter treatment period ( 2 weeks vs 12 weeks) and the ferritin levels were significantly higher. Except for the burning at the injection site, FCM was better tolerated than FS, mostly regarding gastrointestinal AEs. There were no safety concerns identified in breastfed infants.

A retrospective comparative study between FCM and IS in postpartum anemia was carried out in a cohort 210 of anemic inpatient women who received FCM $(15 \mathrm{mg} / \mathrm{kg}$; maximum, 1,000 mg) or IS (2 times $200 \mathrm{mg}$ ), respectively, in the postpartum period. ${ }^{61}$

Both treatments were tolerated with overall AEs of $5 \%$ (FCM) versus 6\% (IS); the most common complaint was burning and pain at the injection site. FCM was as effective as IS in changing $\mathrm{Hb}$ levels from the baseline. There was no difference in the mean daily $\mathrm{Hb}$ increase between the groups. Both drugs were effective and offered a rapid normalization of $\mathrm{Hb}$ after delivery. However, women with severe anemia showed the most effective responsiveness with FCM.

\section{Studies with FCM in surgery patients and other indications}

The efficacy of iv FCM $(1,000 \mathrm{mg})$ in a single dose in 20 anemic patients with colorectal cancer administered at least 14 days before the planned date of surgery was recently evaluated. ${ }^{62} \mathrm{FCM}$ was effective in increasing the $\mathrm{Hb}$ levels significantly and to reduce allogeneic blood transfusion (ABT) requirements.

The efficacy and safety of FCM was also assessed in 281 patients who underwent bariatric surgery in a retrospective analysis from five open-label, multicenter, randomized, controlled studies. ${ }^{63}$ FCM showed similar or improved efficacy $(P<0.05)$ in terms of increasing $\mathrm{Hb}$, ferritin, and TSAT values relative to other iron products used as the standard of care for IDA. These data in IDA patients who had undergone bariatric surgery suggest that FCM is a safe and effective alternative to existing iron products, which permits higher and thus less frequent individual doses.

In a multicenter comparative study, Bisbe et $\mathrm{al}^{64}$ evaluated the efficacy of FCM and IS for reversing preoperative anemia in patients undergoing major elective surgery. Patients with FCM completed iron replenishment faster than those receiving IS $(82 \%$ vs $62 \% P<0.01)$ together with a higher $\mathrm{Hb}$ level, receiving less infusions (two versus five, $P<0.01$ ) and with lower frequency in ABT.

Regarding orthopedic surgery, two recent studies have tested FCM. ${ }^{65,66}$ A randomized, controlled study assessed the effectiveness of iv FCM infusion in patients with post total knee arthroplasty (TKA) anemia. ${ }^{64}$ Post surgery, the anemic patients without prior transfusions received either FCM (700-1,000 mg iron [depending on the calculated iron 
deficit on postoperative day 2]) or oral iron (FS, $100 \mathrm{mg}$ iron daily from day 7 onward). A total of 122 anemic patients (within 24 hours after surgery) were enrolled in that study (FCM, n=60, FS, n=62). The patients with FCM obtained $\mathrm{Hb} \geq 12.0 \mathrm{~g} / \mathrm{dL}$ more often ( $42.3 \%$ vs $23.5 \% ; P=0.04)$ and displayed a tendency to higher $\mathrm{Hb}$ increase from day 4 to day $30(P=0.075)$ versus those with FS. ID patients had a higher $\mathrm{Hb}$ increase with FCM than FS $(P=0.03)$, and those with postoperative $\mathrm{Hb}<10 \mathrm{~g} / \mathrm{dL}$ showed better $\mathrm{Hb}$ response with FCM than FS, $P=0.018$. The conclusion of this study was that iv FCM infusion post surgery was superior to oral FS, mainly in patients with preoperative ID, severe postoperative anemia, or both.

Similarly, Rineau et $a^{67}$ assessed comparatively the treatment of anemic patients who had undergone orthopedic surgery (hip and knee arthroplasty) with oral iron + ESAs versus FCM + ESAs. They concluded that the use of FCM, compared with oral iron, increases ESAs response with an increased discharge of $\mathrm{Hb}$ levels and prevents the depletion of iron stores induced by ESAs.

In other less frequent indications, like in lipoprotein apheresis patients, in whom iron deficiency and IDA are common findings, FCM 500-1,000 $\mathrm{mg}$ as a single shot infusion over 20 minutes was demonstrated to be safe and effective, allowing a faster filling of iron stores. ${ }^{68}$

Two trials evaluated FCM in patients with restless leg syndrome (RLS). One, a double-blinded, multicenter, randomized, parallel-group, placebo-controlled study, compared the safety and efficacy of FCM with placebo in subjects with moderate to severe RLS. ${ }^{69}$ The other was just an observational study. ${ }^{70}$ In both studies, FCM significantly improved the RLS symptoms.

These outcomes are relevant in ordinary clinical practice, particularly for patients with severe RLS symptoms and iron deficiency, in whom a fast and positive response to the FCM infusion may generate favorable modifications in RLS-specific therapy.

\section{Studies evaluating the cost effectiveness of FCM}

Nowadays, the analysis of cost effectiveness for every new therapy is, undoubtedly, of paramount importance. Consequently, various studies have dealt with this issue. Bhandari, ${ }^{71}$ in a comparative analysis of hospital costs, reported that FCM was less expensive not only versus IS but also relative to LMWID. Later, Calvet et al ${ }^{72}$ performed a cost-minimization analysis to evaluate the cost impact of FCM versus IS. The variables included in that analysis were the cost of FCM and IS, indirect costs/hour, staff cost per hour, cost of infusion devices, and nonmedical direct costs. They concluded on this pharmacoeconomical model that FCM infusion was less costly than IS infusion.

Data from 182 matched pairs of total lower limb arthroplasty patients managed with a restrictive transfusion protocol and without (control group) or with post-operative iv iron (iron group) were retrospectively reviewed by Muñoz et al. ${ }^{73}$ The costs of IS or FCM, ABT, Hb measurements, and prolonged stay in hospital were used for the analysis. The main outcomes were that post-operative iv FCM after total lower limb arthroplasty was associated with reduced transfusion rates, without incremental costs.

In an interesting study, Brock et al ${ }^{74}$ estimated the budget impact on the Swiss mandatory health insurance associated with substituting IS (standard) with FCM (new treatment) using real-life data. The resource used was based on primary data (Polyquest Prescriber Analysis, Anemia Patient Record Study in Switzerland), and the authors concluded that FCM was associated with cost savings of $30 \%-44 \%$ per patient per treatment cycle compared to IS. Similar results were reported by Fragoulakis et $\mathrm{al}^{75}$ in their study on an economic evaluation comparing FCM, IS, and LMWID in the management of IDA in Greece. The budget impact analysis for a hospital with 100 patients showed that, in inpatients, the whole cost of FCM was $113 \%$ and $15.4 \%$ lower against IS and LM WIND, respectively, and in outpatients it was $201.1 \%$ and $151.8 \%$ lower versus their comparators.

\section{Clinical and experimental information on the safety profile of FCM}

Since iv iron may cause a variable degree of toxicity, a number of experimental studies in basic science have been performed in order to evaluate the safety profile of FCM. ${ }^{76-79}$ In this sense, a comparative study of FCM versus other iv iron preparations (FG, IS, HMWID, and LMWID) demonstrated that after a similar dose of iv iron (weekly administration for 4 weeks) to nonanemic rats, FCM presents a better profile with respect to FG, HMWID, and LMWID on oxidative stress and inflammatory markers in tissue (liver, heart and kidney) ${ }^{76}$ Furthermore, in another study in rodents, FCM administration did not result in detectable levels of nitrotyrosine (marker of nitrosative stress) or significant levels of caspase 3 (apoptosis) in liver, heart, or kidney, versus control. ${ }^{79}$

In clinical investigation, a direct comparison study on the safety of FCM versus iron dextran in patients with IDA was conducted by Hussain et al. ${ }^{80}$ Most of the patients were 
women, whose principal cause of anemia was HUB, IBD, or other gastrointestinal pathologies. FCM increased $\mathrm{Hb}$ levels, replenished iron stores, and had a low incidence of AEs. In this study, there was also a lower rate of allergic reactions in the FCM group with respect to the iron dextran group. The trial confirmed the safety profile of FCM in comparison with another frequently administered iv iron, iron dextran. Moreover, Onken et $\mathrm{al}^{81}$ have recently evaluated the efficacy and safety of FCM versus oral iron and versus standard care iv therapy in IDA patients who had presented inadequate response to oral iron after a 2 -week treatment. Safety endpoints occurred in $3.4 \%$ in the FCM group versus $3.2 \%$ in the comparator groups. In conclusion, two $750 \mathrm{mg}$ FCM infusions were safe and superior to oral iron in improving $\mathrm{Hb}$ in this cohort of patients.

Although the mechanism remains unknown, potential negative consequences on bone metabolism (hypophosphatemia and alterations in fibroblast growth factor 23 (FGF23) plasma level) have been attributed to iv iron therapies, including FCM. Some recent clinical and experimental data have contributed to clarify this controversial topic. In a post hoc analysis of a prospective study carried out in 47 NDD-CKD patients with IDA who had received a single 1,000-mg injection of FCM, Prats et al ${ }^{82}$ examined the effect of FCM on phosphate metabolism and FGF23 levels in patients with CKD using markers of mineral metabolism. They concluded that in NDD-CKD patients, FCM induced a reduction in serum phosphate levels that persisted for 3 months. Moreover, FCM produced a substantial reduction in FGF23 levels without modifications in other bone metabolism markers. Furthermore, in non-irondepleted normal and uremic rats, a single high dose of FCM had no effect on the plasma levels of FGF23 and phosphate for up to 7 days. ${ }^{83}$

It has been suggested for years that iv iron may impair host defense and promote bacterial growth, although the risk of infection associated with iron supplementation is controversial. Fell et al ${ }^{84}$ assessed the "in vitro" effect of different concentrations of ICCs including FCM on stimulated mature monocytes and hematopoietic $\mathrm{CD} 34^{+}$stem cells during their differentiation into monocytes and phagocytosis and antigen presentation capacity. The authors reported no substantial specific immunologic effects after FMC stimulation, with no significant alterations in the differentiation of monocytes from hematopoietic CD34 ${ }^{+}$stem cells. Moreover, FCM did not affect the expression of CD14, CD16, or CD86 in human monocyte subsets collected from control subjects without overt CKD.
Notably, using a standard experimental model of malarial anemia, Maretty et al ${ }^{85}$ studied the effect of FCM treatment on erythropoiesis, parasitemia, and weight as a marker of disease severity. They reported that FCM did not have a negative effect on parasitemia and disease progression. FCM resulted in significantly higher animal weights, enhanced reticulocytosis, and faster recovery in comparison with controls.

Concerning the safety of FCM administration during pregnancy, the transplacental passage of FCM (radio-labeled with ${ }^{59} \mathrm{Fe}$ ) was evaluated in an "in vitro" perfusion model of human placenta. ${ }^{86} \mathrm{FCM}$ was added to the maternal circuit in order to obtain a final iron concentration of $11 \mathrm{mM}$, which represents a 10 times higher iron concentration than the maximum predicted level in blood after an administration of $200 \mathrm{mg}$ iron as FCM. No transferred iron radioactivity was detected in the fetal circuit. Importantly, there were no effects of FCM on placental permeability and other placental functions. In conclusion, FCM did not cross the placenta.

\section{Quality of life in patients treated with FCM}

Various studies with FCM have included diverse evaluations on the changes in QoL. All of them have reported an improvement in QoL. Just to mention some of them, in the field of cardiovascular medicine, Comin-Colet et al ${ }^{47}$ performed a subanalysis of the previously published FAIR-HF study. ${ }^{43}$ They assessed baseline QoL in iron deficiency patients with CHF and the outcome of FCM on QoL. FCM remarkably improved QoL after 4 weeks and during the remaining study period. The favorable effects of FCM were independent of the anemia status. In line with this, another subanalysis on the FAIR-HF study was conducted by Gutzwiller et $\mathrm{al}^{46}$ in which a multivariate analysis was carried out with various clinical variables as independent variables and QoL measures as dependent variables. They concluded that the treatment with FCM positively influenced the measures of QoL in patients with HF and ID.

Chronic fatigue is a regrettable condition affecting QoL. A randomized, placebo-controlled, single-blinded study tested the effectiveness and tolerability of a single dose of iv FCM in iron-deficient premenopausal women with symptomatic unexplained fatigue. Fatigued women with iron deficiency (ferritin $<50 \mu \mathrm{g} / \mathrm{L}$ and TSAT $<20 \%$, or ferritin $<15 \mu \mathrm{g} / \mathrm{L})$ and normal or borderline $\mathrm{Hb}(\geq 11.5 \mathrm{~g} / \mathrm{dL})$ were enrolled in 21 sites in Europe, blinded to the study drug and randomized (computer-generated randomization sequence) to a single FCM (1,000 mg iron) or saline (placebo) infusion. ${ }^{87} \mathrm{FCM}$ enhanced fatigue, mental QoL, cognitive 
function, and erythropoiesis in iron-deficient women with normal or borderline $\mathrm{Hb}$.

\section{Conclusion}

In numerous medical conditions in the wide scenario of clinical practice, the actual need to supply high doses of iron in a relatively short time is of paramount importance. Therefore, the improvement of the iron delivery by using a suitable therapeutic tool is a real challenge in current pharmacology. Moreover, adequate trade-off between fast iron delivery and its rapid cell incorporation - this mainly to facilitate not only red blood cell production but also to establish other essential metabolic cellular functions in diverse tissue - and the potential occurrence of severe adverse side effects is undoubtedly a matter of concern for pharmacologists.

FCM is a robust and stable molecule with similar characteristics to ferritin, which minimizes the release of free iron during its administration, this allows greater iron delivery to tissues and a faster repletion of iron stores by a single infusion, with favorable cost effectiveness. Furthermore, since FCM is a dextran-free ICC, it does not react with dextran antibodies, thus resulting in a very low risk for hypersensitivity reactions.

Recently, FCM has generated a growing number of clinical studies on its effectiveness and safety in a wide range of indications, including patients with CHF, postpartum anemia/abnormal uterine bleeding, IBD, NDD-CKD, and those undergoing hemodialysis (HD). In addition, safety data from almost 6,000 patients have shown that FCM has been well tolerated. This cumulated information has contributed to support the recent approval by the FDA to use FCM for the treatment of IDA in adult patients who are intolerant of oral iron or present an unsatisfactory response to oral iron, and in adult patients with NDD-CKD. ${ }^{88}$ Finally, taking into account the need of optimizing iron delivery to tissues, currently available data suggest that FCM seems to be an effective, safe, and well-tolerated option in the treatment of iron deficiency in its broad spectrum.

\section{Acknowledgment}

The authors would like to thank Ms Jacqueline Mastantuono, who kindly reviewed the style of this manuscript.

\section{Disclosure}

Jorge Eduardo Toblli has received research grants and consultancy fees from Vifor Pharma Ltd. Margarita Angerosa reports no conflict of interest in this work.

\section{References}

1. McLean E, Cogswell M, Egli I, Wojdyla D, de Benoist B. Worldwide prevalence of anaemia, WHO Vitamin and Mineral Nutrition Information System, 1993-2005. Public Health Nutr. 2009;12(4):444-454.

2. Gaskell H, Derry S, Andrew Moore R, McQuay HJ. Prevalence of anaemia in older persons: systematic review. BMC Geriatr. 2008;8:1.

3. National Institute for Health and Clinical Excellence. Anaemia management in people with chronic kidney disease (CKD). NICE Clinical Guideline [Clinical Guideline 114]; 2011. Available from: http://guidance.nice.org.uk/cg114

4. Stoltzfus RJ. Defining iron-deficiency anemia in public health terms: a time for reflection. J Nutr. 2001;131(2S-2S):565S-567S.

5. von Drygalski A, Adamson JW. Ironing out fatigue. Blood. 2011;118: 3191-3192.

6. Goodnough LT. Iron deficiency syndromes and iron-restricted erythropoiesis (CME). Transfusion. 2012;52(7):1584-1592.

7. Kohgo Y, Ikuta K, Ohtake T, Torimoto Y, Kato J. Body iron metabolism and pathophysiology of iron overload. Int $J$ Hematol. 2008;88(1):7-15.

8. Institute of Medicine (US) Panel on Micronutrients. Dietary Reference Intakes for Vitamin A, Vitamin K, Arsenic, Boron, Chromium, Copper, Iodine, Iron, Manganese, Molybdenum, Nickel, Silicon, Vanadium, and Zinc. Washington, DC: National Academies Press (US); 2001.

9. Shah YM, Matsubara T, Ito S, Yim SH, Gonzalez FJ. Intestinal hypoxiainducible transcription factors are essential for iron absorption following iron deficiency. Cell Metab. 2009;9(2):152-164.

10. Wang J, Pantopoulos K. Regulation of cellular iron metabolism. Biochem J. 2011;434(3):365-381.

11. Shayeghi M, Latunde-Dada GO, Oakhill JS, et al. Identification of an intestinal heme transporter. Cell. 2005;122(5):789-801.

12. Quigley JG, Yang Z, Worthington MT, et al. Identification of a human heme exporter that is essential for erythropoiesis. Cell. 2004; 118(6):757-766

13. West AR, Oates PS. Mechanisms of heme iron absorption: current questions and controversies. World J Gastroenterol. 2008; 14(26):4101-4110.

14. Abboud S, Haile DJ. A novel mammalian iron-regulated protein involved in intracellular iron metabolism. J Biol Chem. 2000; 275(26):19906-19912.

15. Loréal O, Cavey T, Bardou-Jacquet E, Guggenbuhl P, Ropert M, Brissot P. Iron, hepcidin, and the metal connection. Front Pharmacol. 2014;5:128.

16. Pak M, Lopez MA, Gabayan V, Ganz T, Rivera S. Suppression of hepcidin during anemia requires erythropoietic activity. Blood. 2006;108(12):3730-3735.

17. Fleming RE. Iron and inflammation: cross-talk between pathways regulating hepcidin. J Mol Med. 2008;86(5):491-494.

18. Knutson MD, Oukka M, Koss LM, Aydemir F, Wessling-Resnick M. Iron release from macrophages after erythrophagocytosis is up-regulated by fer roport in 1 overexpression and down-regulated by hepcidin. Proc Natl Acad Sci U S A. 2005;102(5):1324-1328.

19. Theurl I, Fritsche G, Ludwiczek S, Garimorth K, Bellmann-Weiler R, Weiss G. The macrophage: a cellular factory at the interphase between iron and immunity for the control of infections. Biometals. 2005; 18(4):359-367.

20. Potdar AA, Sarkar J, Das NK, et al. Computational modeling and analysis of iron release from macrophages. PLoS Comput Biol. 2014; 10(7):e1003701.

21. Bartnikas TB, Andrews NC, Fleming MD. Transferrin is a major determinant of hepcidin expression in hypotransferrinemic mice. Blood. 2011;117(2):630-637.

22. Funk F, Ryle P, Canclini C, Neiser S, Geisser P. The new generation of intravenous iron: chemistry, pharmacology, and toxicology of ferric carboxymaltose. Arzneimittelforschung. 2010;60(6a):345-353.

23. Auerbach M, Ballard H. Clinical use of intravenous iron: administration, efficacy, and safety. Hematology Am Soc Hematol Educ Program. 2010;2010(1):338-347. 
24. Koskenkorva-Frank TS, Weiss G, Koppenol WH, Burckhardt S. The complex interplay of iron metabolism, reactive oxygen species, and reactive nitrogen species: insights into the potential of various iron therapies to induce oxidative and nitrosative stress. Free Radic Biol Med. 2013;65:1174-1194.

25. Sohn YS, Ghoti H, Breuer W, et al. The role of endocytic pathways in cellular uptake of plasma non-transferrin iron. Haematologica. 2012; 97(5):670-678.

26. Chao Y, Karmali PP, Simberg D. Role of carbohydrate receptors in the macrophage uptake of dext ran-coated iron oxide nanoparticles. Adv Exp Med Biol. 2012;733:115-123.

27. Neiser S, Wilhelm M, Schwarz K, Funk F, Geisser P, Burckhardt S. Assessment of dextran antigenicity of intravenous iron products by immunodiffusion assay. Port J Nephrol Hypertens. 2011; 25 : 219-224.

28. Geisser $\mathrm{P}$, Burckhardt $\mathrm{S}$. The pharmacokinetics and pharmacodynamics of iron preparat ions. Pharmaceutics. 2011;3(1):12-33.

29. Danielson BG. Structure, chemistry, and pharmacokinetics of intravenous iron agents. J Am Soc Nephrol. 2004;15(suppl 2):S93-S98.

30. Bailie GR, Mason NA, Valaoras TG. Safety and tolerability of intravenous ferric carboxymaltose in patients with iron deficiency anemia. Hemodial Int. 2010;14(1):47-54.

31. Ohgami RS, Campagna DR, Greer EL, et al. Identification of a ferrireductase required for efficient transferrin-dependent iron uptake in erythroid cells. Nat Genet. 2005;37(11):1264-1269.

32. Geisser P, Banke-Bochita J. Pharmacokinetics, safety and tolerability of intravenous ferric carboxymaltose: a dose escalation study in volunteers with mild iron-deficiency anaemia. Arzneimittelforschung. 2010;60(6a):362-372.

33. Geisser P, Rumyantsev V. Pharmacodynamics and safety of ferric carboxymaltose: a multiple-dose study in patients with iron-deficiency anaemia secondary to a gastrointestinal disorder. Arzneimittelforschung. 2010;60(6a):373-385.

34. Beshara S, Sörensen J, Lubberink M, et al. Pharmacokinetics and red cell utilization of ${ }^{52} \mathrm{Fe} /{ }^{/ 9} \mathrm{Fe}$-labelled iron polymaltose in anaemic patients using positron emission tomography. Br J Haematol. 2003; 120(5):853-859.

35. Breymann C, Gliga F, Bejenariu C, Strizhova N. Comparative efficacy and safety of intravenous ferric carboxymaltose in the treatment of postpartum iron deficiency anemia. Int J Gynaecol Obstet. 2008; 101(1):67-73

36. Kalantar-Zadeh K, Lee GH, Miller JE, et al. Predictors of hyporesponsiveness to erythropoiesis-stimulating agents in hemodialysis patients. Am J Kidney Dis. 2009;53(5):823-834.

37. Covic A, Mircescu G. The safety and efficacy of intravenous ferric carboxymaltose in anaemic patients undergoing haemodialysis: a multi-centre, open-label, clinical study. Nephrol Dial Transplant. 2010;25(8):2722-2730

38. Charytan C, Bernardo MV, Koch TA, Butcher A, Morris D, Bregman DB. Intravenous ferric carboxymaltose versus standard medical care in the treatment of iron deficiency anemia in patients with chronic kidney disease: a randomized, active-controlled, multi-center study. Nephrol Dial Transplant. 2013;28(4):953-964.

39. Onken JE, Bregman DB, Harrington RA, et al. Ferric carboxymaltose in patients with iron-deficiency anemia and impaired renal function: the REPAIR-IDA trial. Nephrol Dial Transplant. 2014;29(4): 833-842.

40. Qunibi WY, Martinez C, Smith M, Benjamin J, Mangione A, Roger SD. A randomized controlled trial comparing intravenous ferric carboxymaltose with oral iron for treatment of iron deficiency anaemia of non-dialysis-dependent chronic kidney disease patients. Nephrol Dial Transplant. 2011;26(5):1599-1607.

41. Macdougall IC, Bock AH, Carrera F, et al; FIND-CKD Study Investigators. FIND-CKD: a randomized trial of intravenous ferric carboxymaltose versus oral iron in patients with chronic kidney disease and iron deficiency anemia. Nephrol Dial Transplant. 2014;29(11): 2075-2084.
42. Grimmelt AC, Cohen CD, Fehr T, Serra AL, Wuethrich RP. Safety and tolerability of ferric carboxymaltose (FCM) for treatment of iron deficiency in patients with chronic kidney disease and in kidney transplant recipients. Clin Nephrol. 2009;71(2):125-129.

43. Anker SD, Comin Colet J, Filippatos G, et al; FAIR-HF Trial Investigators. Ferric carboxymaltose in patients with heart failure and iron deficiency. N Engl J Med. 2009;361(25):2436-2448.

44. Van Craenenbroeck EM, Conraads VM, Greenlaw N, et al. The effect of intravenous ferric carboxymaltose on red cell distribution width: a subanalysis of the FAIR-HF study. Eur J Heart Fail. 2013; 15(7):756-762.

45. Filippatos G, Farmakis D, Colet JC, et al. Intravenous ferric carboxymaltose in iron-deficient chronic heart failure patients with and without anaemia: a subanalysis of the FAIR-HF trial. Eur J Heart Fail. 2013; 15(11):1267-1276.

46. Gutzwiller FS, Pfeil AM, Comin-Colet J, et al. Determinants of quality of life of patients with heart failure and iron deficiency treated with ferric carboxymaltose: FAIR-HF sub-analysis. Int J Cardiol. 2013; 168(4):3878-3883.

47. Comin-Colet J, Lainscak M, Dickstein K, et al. The effect of intravenous ferric carboxymaltose on health-related quality of life in patients with chronic heart failure and iron deficiency: a subanalysis of the FAIR-HF study. Eur Heart J. 2013;34(1):30-38.

48. Ponikowski P, van Veldhuisen DJ, Comin-Colet J, et al; for the CONFIRM-HF Investigators. Beneficial effects of long-term intravenous iron therapy with ferric carboxymaltose in patients with symptomatic heart failure and iron deficiency. Eur Heart J. 2014.

49. Kulnigg S, Stoinov S, Simanenkov V, et al. A novel intravenous iron formulation for treatment of anemia in inflammatory bowel disease: the ferric carboxymaltose (FERINJECT) randomized controlled trial. Am J Gastroenterol. 2008;103(5):1182-1192.

50. Befrits R, Wikman O, Blomquist L, et al. Anemia and iron deficiency in inflammatory bowel disease: an open, prospective, observational study on diagnosis, treatment with ferric carboxymaltose and quality of life. Scand J Gastroenterol. 2013;48(9):1027-1032.

51. Kulnigg-Dabsch S, Schmid W, Howaldt S, et al. Iron deficiency generates secondary thrombocytosis and platelet activation in IBD: the randomized, controlled thromboVIT trial. Inflamm Bowel Dis. 2013;19(8):1609-1616.

52. Evstatiev R, Marteau P, Iqbal T, et al; FERGI Study Group. FERGIcor, a randomized controlled trial on ferric carboxymaltose for iron deficiency anemia in inflammatory bowel disease. Gastroenterology. 2011; 141(3):846-853.

53. Evstatiev R, Alexeeva O, Bokemeyer B, et al; FERGI Study Group. Ferric carboxymaltose prevents recurrence of anemia in patients with inflammatory bowel disease. Clin Gastroenterol Hepatol. 2013;11(3): 269-277.

54. Reim D, Kim YW, Nam BH, et al. FAIRY: a randomized controlled patient-blind phase III study to compare the efficacy and safety of intravenous ferric carboxymaltose $\left(\right.$ Ferinject $\left.{ }^{\circledR}\right)$ to placebo in patients with acute isovolemic anemia after gastrectomy - study protocol for a randomized controlled trial. Trials. 2014;15:111.

55. Van Wyck DB, Mangione A, Morrison J, Hadley PE, Jehle JA, Goodnough LT. Large-dose intravenous ferric carboxymaltose injection for iron deficiency anemia in heavy uterine bleeding: a randomized, controlled trial. Transfusion. 2009;49(12):2719-2728.

56. Herfs R, Fleitmann L, Kocsis I. Treatment of Iron deficiency with or without anaemia with intravenous ferric carboxymaltose in gynaecological practices - a non-interventional study. Geburtshilfe Frauenheilkd. 2014;74(1):81-88.

57. Christoph P, Schuller C, Studer H, Irion O, De Tejada BM, Surbek D. Intravenous iron treatment in pregnancy: comparison of high-dose ferric carboxymaltose vs iron sucrose. J Perinat Med. 2012; 40(5):469-474.

58. Froessler B, Collingwood J, Hody NA, Dekker G. Intravenous ferric carboxymaltose for anaemia in pregnancy. BMC Pregnancy Childbirth. 2014; $14: 115$. 
59. Van Wyck DB, Martens MG, Seid MH, Baker JB, Mangione A. Intravenous ferric carboxymaltose compared with oral iron in the treatment of postpartum anemia: a randomized controlled trial. Obstet Gynecol. 2007;110(2 pt 1):267-278.

60. Seid MH, Derman RJ, Baker JB, Banach W, Goldberg C, Rogers R. Ferric carboxymaltose injection in the treatment of postpartum iron deficiency anemia: a randomized controlled clinical trial. Am J Obstet Gynecol. 2008;199(4):435.e1-435.e7.

61. Pfenniger A, Schuller C, Christoph P, Surbek D. Safety and efficacy of high-dose intravenous iron carboxymaltose vs iron sucrose for treatment of postpartum anemia. J Perinat Med. 2012;40(4):397-402.

62. Keeler BD, Simpson JA, Ng S, et al. The feasibility and clinical efficacy of intravenous iron administration for preoperative anaemia in patients with colorectal cancer. Colorectal Dis. 2014;16(10):794-800.

63. Malone M, Barish C, He A, Bregman D. Comparative review of the safety and efficacy of ferric carboxymaltose versus standard medical care for the treatment of iron deficiency anemia in bariatric and gastric surgery patients. Obes Surg. 2013;23(9):1413-1420.

64. Bisbe E, García-Erce JA, Díez-Lobo AI, Muñoz M; Anaemia Working Group España. A multicentre comparative study on the efficacy of intravenous ferric carboxymaltose and iron sucrose for correcting preoperative anaemia in patients undergoing major elective surgery. Br J Anaesth. 2011;107(3):477-478.

65. Bisbe E, Moltó L, Arroyo R, Muniesa JM, Tejero M. Randomized trial comparing ferric carboxymaltose vs oral ferrous glycine sulphate for postoperative anaemia after total knee arthroplasty. Br J Anaesth. 2014; 113(3):402-409

66. Steinmetz T, Tschechne B, Harlin O, et al. Clinical experience with ferric carboxymaltose in the treatment of cancer- and chemotherapyassociated anaemia. Ann Oncol. 2013;24(2):475-482.

67. Rineau E, Chaudet A, Carlier L, Bizot P, Lasocki S. Ferric carboxymaltose increases epoetin- $\alpha$ response and prevents iron deficiency before elective orthopaedic surgery. Br J Anaesth. 2014;113(2):296-298.

68. Schatz U, Arneth B, Siegert G, et al. Iron deficiency and its management in patients undergoing lipoprotein apheresis. Comparison of two parenteral iron formulations. Atheroscler Suppl. 2013;14(1):115-122.

69. Allen RP, Adler CH, Du W, Butcher A, Bregman DB, Earley CJ. Clinical efficacy and safety of IV ferric carboxymaltose (FCM) treatment of RLS: a multi-centred, placebo-controlled preliminary clinical trial. Sleep Med. 2011;12(9):906-913.

70. Hornyak M, Scholz H, Kiemen A, Kassubek J. Investigating the response to intravenous iron in restless legs syndrome: an observational study. Sleep Med. 2012;13(6):732-735.

71. Calvet X, Ruíz MÀ, Dosal A, et al. Cost-minimization analysis favours intravenous ferric carboxymaltose over ferric sucrose for the ambulatory treatment of severe iron deficiency. PLoS One. 2012;7(9):e45604.

72. Bhandari S. Update of a comparative analysis of cost minimization following the introduction of newly available intravenous iron therapies in hospital practice. Ther Clin Risk Manag. 2011;7:501-509.

73. Muñoz M, Gómez-Ramírez S, Martín-Montañez E, Naveira E, Seara J, Pavía J. Cost of post-operative intravenous iron therapy in total lower limb arthroplasty: a retrospective, matched cohort study. Blood Transfus. 2014;12(1):40-49.
74. Brock E, Braunhofer P, Troxler J, Schneider H. Budget impact of parenteral iron treatment of iron deficiency: methodological issues raised by using real-life data. Eur J Health Econ. Epub 2014 Dec.

75. Fragoulakis V, Kourlaba G, Goumenos D, Konstantoulakis M, Maniadakis N. Economic evaluation of intravenous iron treatments in the management of anemia patients in Greece. Clinicoecon Outcomes Res. 2012;4: 127-134

76. Toblli JE, Cao G, Olivieri L, Angerosa M. Comparison of the renal, cardiovascular and hepatic toxicity data of original intravenous iron compounds. Nephrol Dial Transplant. 2010;25(11):3631-3640.

77. Toblli JE, Cao G, Oliveri L, Angerosa M. Assessment of the extent of oxidative stress induced by intravenous ferumoxytol, ferric carboxymaltose, iron sucrose and iron dextran in a nonclinical model. Arzneimittelforschung. 2011;61(7):399-410.

78. Toblli JE, Rivas C, Cao G, et al. Ferric carboxymaltose-mediated attenuation of Doxorubicin-induced cardiotoxicity in an iron deficiency rat model. Chemother Res Pract. 2014;2014:570241.

79. Toblli JE, Cao G, Giani JF, Dominici FP, Angerosa M. Nitrosative stress and apoptosis by intravenous ferumoxytol, iron isomaltoside 1000, iron dextran, iron sucrose, and ferric carboxymaltose in a nonclinical model. Drug Res (Stuttg). Epub 2014 Jul 22.

80. Hussain I, Bhoyroo J, Butcher A, Koch TA, He A, Bregman DB. Direct comparison of the safety and efficacy of ferric carboxymaltose versus iron dextran in patients with iron deficiency anemia. Anemia. 2013; 2013:169107.

81. Onken JE, Bregman DB, Harrington RA, et al. A multicenter, randomized, active-controlled study to investigate the efficacy and safety of intravenous ferric carboxymaltose in patients with iron deficiency anemia. Transfusion. 2014;54(2):306-315.

82. Prats M, Font R, García C, Cabré C, Jariod M, Vea AM. Effect of ferric carboxymaltose on serum phosphate and C-terminal FGF23 levels in non-dialysis chronic kidney disease patients: post-hoc analysis of a prospective study. BMC Nephrol. 2013;14:167.

83. Gravesen E, Hofman-Bang J, Mace ML, Lewin E, Olgaard K. High dose intravenous iron, mineral homeostasis and intact FGF23 in normal and uremic rats. BMC Nephrol. 2013;14:281.

84. Fell LH, Zawada AM, Rogacev KS, Seiler S, Fliser D, Heine GH Distinct immunologic effects of different intravenous iron preparations on monocytes. Nephrol Dial Transplant. 2014;29(4):809-822.

85. Maretty L, Sharp RE, Andersson M, Kurtzhals JA. Intravenous ferric carboxymaltose accelerates erythropoietic recovery from experimental malarial anemia. J Infect Dis. 2012;205(7):1173-1177.

86. Malek A. In vitro studies of ferric carboxymaltose on placental permeability using the dual perfusion model of human placenta. Arzneimittelforschung. 2010;60(6a):354-361.

87. Favrat B, Balck K, Breymann C, et al. Evaluation of a single dose of ferric carboxymaltose in fatigued, iron-deficient women - PREFER a randomized, placebo-controlled study. PLoS One. 2014;9(4):e94217.

88. Thompson CA. Ferric carboxymaltose approved for iron deficiency anemia. Am J Health Syst Pharm. 2013;70(17):1458.

\section{Publish your work in this journal}

Drug Design, Development and Therapy is an international, peerreviewed open-access journal that spans the spectrum of drug design and development through to clinical applications. Clinical outcomes, patient safety, and programs for the development and effective, safe, and sustained use of medicines are a feature of the journal, which

\section{Dovepress}

has also been accepted for indexing on PubMed Central. The manuscript management system is completely online and includes a very quick and fair peer-review system, which is all easy to use. Visit http://www.dovepress.com/testimonials.php to read real quotes from published authors. 